\title{
Large scale atmospheric contribution of trace elements registered in foliose lichens in remote French areas
}

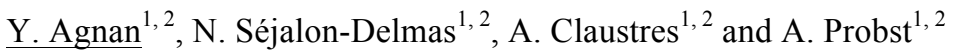 \\ ${ }^{1}$ Université de Toulouse ; INP, UPS ; EcoLab (Laboratoire Ecologie fonctionnelle et Environnement) ; ENSAT, \\ Avenue de l'Agrobiopôle, F-31326 Castanet-Tolosan, France \\ ${ }^{2}$ CNRS ; EcoLab ; F-31326 Castanet-Tolosan, France, anne.probst@ensat.fr
}

\begin{abstract}
The human activities affect atmospheric compartment by trace elements emissions. The evaluation of atmospheric deposition can be performed by means of bioaccumulator organisms. In this study, we investigated two lichen species (Xanthoria parietina and Parmelia sulcata) from five remote areas far from local sources of contamination in France. PCA and enrichment factor were used to set up the geochemical background of 16 trace elements (including metals and metalloids). Some elements known to be influenced by anthropogenic activities, merge into the geochemical background, like As. The enrichment factors showed a high enrichment for $\mathrm{Sb}, \mathrm{Cd}, \mathrm{Zn}, \mathrm{As}, \mathrm{Cu}$, and $\mathrm{Pb}$, and to a less extent $\mathrm{Sn}$ and $\mathrm{Mn}$. Others elements were associated to lithogenic contribution, including particularly As. A significant gradient from the South to the North-East was observed, convergently to the increased concentration registered in soils.
\end{abstract}

Key words: lichens, heavy metals, atmospheric deposition, Xanthoria parietina, Parmelia sulcata

\section{Introduction}

Since industrial period, human activities impacted all the environmental compartments by trace elements (As, Cd, Sb...). The natural biogeochemical cycling of these elements is nowadays disturbed (Rauch \& Pacyna, 2009), up to find them in environment far away from any pollution sources (Wolff et al., 1999; Lee et al., 2008). Atmospheric depositions of trace elements are a significant input into the ecosystems (Ulrich and Pankrath, 1983) with potential toxicological risks.

The evaluation of atmospheric deposition of these elements is complex, due to very low concentrations in dry and wet deposition. In this way, their accumulation into biological organisms overcomes this trouble (Falla et al., 2000; Wolterbeek, 2002). Several biological groups - like lichens or mosses - are well known to be good candidates for bioaccumulation because they accumulate more pollutants than vascular plants (Loppi et al., 1997). This is related to their biological and physiological features (Conti and Cecchetti, 2001). Atmospheric pollutants accumulated by lichen originate from both local and long-range influence (Garty, 2001). Most of the studies used lichens to evaluate manmade contribution in local scale (Loppi et al., 2000; Rusu et al., 2006). However, very few studies have used lichens to evaluate the background levels relative to long-range atmospheric transport (Nimis et al., 2000; Brunialti and Frati, 2007). This study aimed to evaluate the geochemical background of atmospheric deposition of 16 trace elements using foliose lichens in remote areas in France.

\section{Materials and Methods}

This study concerns five French forest areas located far from local contamination sources (Fig. 1). The average rainfall ranges between 800 to $1200 \mathrm{~mm}$ with altitude between $350 \mathrm{~m}$ a.s.l. and $1200 \mathrm{~m}$ a.s.l. (HET54a < EPC08 < EPC63 < SP11 < EPC74). Each station contained five samples composed of a mixture of two foliose lichen species: Xanthoria parietina and Parmelia sulcata, species well known to accumulate trace elements (Garty, 2001 ; Nimis et al., 2000). Lichens thallus were collected at about $1.5 \mathrm{~m}$ high on several regional species tree trunks, with the aim to rise the representativness of the area. Sampling procedure required a special attention to avoid any contamination: sampling with ceramic knife and latex gloves, conservation in plastic bags.

After drying and grinding, mineralization procedure of lichens samples was performed on $100 \mathrm{mg}$ in cleanroom using a $\mathrm{HNO}_{3} / \mathrm{HF} / \mathrm{H}_{2} \mathrm{O}_{2}$ mixture in Teflon vessel (Rusu, 2002). For each series, the performance of the procedure was evaluated using two replicates of three 
certified materials (lichen IAEA-336, pine needle SRM-1575a, and peach leaves SRM-1547) and two blank samples. Trace elements were analyzed by ICP-MS (DL between 1 and $10 \mathrm{ng} \cdot \mathrm{L}^{-1}$ ).

The correlations between elements was valuated with a PCA for all the stations. The enrichment factor (EF) was often used to evaluate the intensity of metal contamination (Bergamaschi et al., 2002 ; Vieira et al., 2004). It is calculated as follows:

$$
\mathrm{EF}=\frac{(\mathrm{X} / \mathrm{Al})_{\text {sample }}}{(\mathrm{X} / \mathrm{Al})_{\mathrm{UCC}}}
$$

with X: element of concern,

$\mathrm{Al}$ : aluminium, reference element from natural origin (Viera et al., 2004),

UCC: upper continental crust, reference material from natural origin (Taylor and McLennan, 1985).

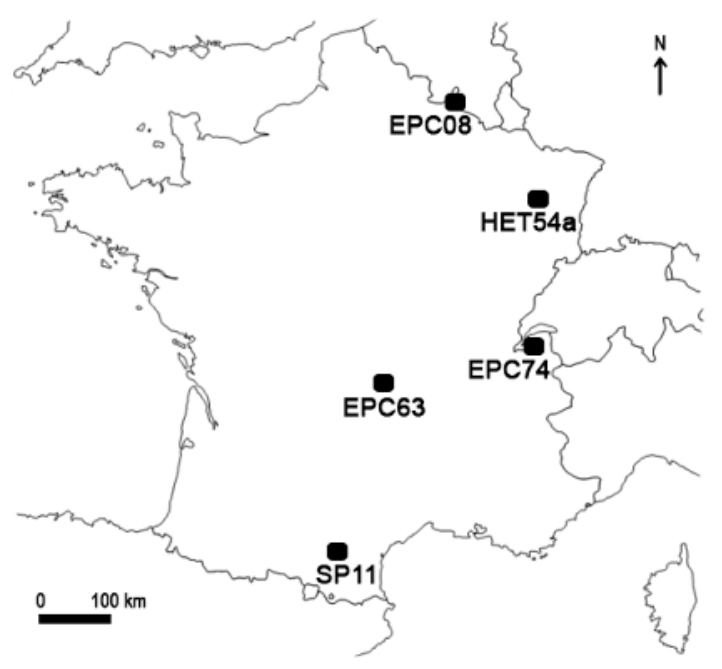

Fig. 1. Location of the French remote study areas for lichen sampling

\section{Results and Discussion}

The relationships between elements allow defining origin and/or behavior similarities. They were done for all the stations through PCA for 16 trace elements (Fig. 2). Four sets of elements could be distinguished: (i) the first group was mainly influenced by the first factor $(39.3 \%$ ) with $\mathrm{Al}$, $\mathrm{As}, \mathrm{Cr}, \mathrm{Fe}$, Ti, and $\mathrm{V}$, (ii) the second one was under the influence of the second factor $(19.2 \%)$ with $\mathrm{Cd}, \mathrm{Cu}, \mathrm{Pb}$, and $\mathrm{Zn}$, (iii) the third group has an intermediate influence (Co, Ni, Sb, and $\mathrm{Sn}$ ), and (iv) $\mathrm{Mn}$ and $\mathrm{Sr}$ with a central position.

The first group included elements known to have a lithogenic origin like Al, Fe, or Ti (Bargagli et al., 2002; Szczepaniak and Biziuk, 2003), except for As. This involved an As chemical form associated with clays and oxides (Fe and Al) (Matschullat, 2000). The second factor, with $\mathrm{Cd}, \mathrm{Cu}, \mathrm{Pb}$, and $\mathrm{Zn}$, seemed to illustrate one anthropogenic contribution. Indeed, even in these most remote areas, a manmade influence could be discriminate, through airborne particulate (Chiarenzelli et al., 2001). It should be noticed that $\mathrm{Cd}$ and $\mathrm{Zn}$ were associated, frequently found in the literature, explained by their physicochemical likenesses despite their distinct origin and biological affinity (Nimis et al., 2000; Brunialti and Frati, 2007; Gandois et al., 2010).

Between these two extremes, four elements $(\mathrm{Co}, \mathrm{Ni}$, $\mathrm{Sb}$, and $\mathrm{Sn}$ ) showed a mixed behavior. However, the third factor $(12.6 \%$, value close to the factor 2) dissociated this set into two groups: $\mathrm{Sb}-\mathrm{Sn}$ vs $\mathrm{Co}-\mathrm{Ni}$. This required an additional source for the robust pair $\mathrm{Sb}-\mathrm{Sn}$, as well as for $\mathrm{Sr}$ and $\mathrm{Cu}$, opposed to the latter (another anthropogenic source, biological interaction...). The EFs allow distinguishing the elements from natural sources (EF close to 1) from elements with a supplementary pressure $(\mathrm{EF}>10)$, like anthropogenic sources. They was calculated for 13 elements for the five areas studied (Fig. 3). Enrichments vary according to the station: the Pyrenean station (SP11) was distinguished by the lowest enrichments. This was probably due to two combined effects, the higher concentrations of $\mathrm{Al}$ and other lithogenic elements, and the lower concentrations in the anthropogenic elements. This requires awareness about the importance of normalization (UCC in this paper). However, the northeastern and eastern regions of France (EPC08, HET54a, and EPC74) were systematically the most impacted areas, which converged with observations in surface layers of forest soils (Hernandez et al., 2003).

Overall, with few exceptions, the more enriched elements $(\mathrm{EF}>10)$, like $\mathrm{Sb}, \mathrm{Cd}$, or $\mathrm{Pb}$, were merged into the anthropogenic group defined above. Conversely, elements with $\mathrm{EF}<10$ (Fe, $\mathrm{Co}, \mathrm{Ti} . .$.$) were included in$ the lithogenic group. The feature of As enrichment (values about 20 and even levels among areas) supported the idea of a geochemical background related to clays affinity. However, $\mathrm{Cd}, \mathrm{Pb}$, or $\mathrm{Mn}$ were more changing among stations. These elements were less influenced by the geochemical background.

\section{Conclusion}

Lichens studied in remote areas were used to define the regional atmospheric background. In this way, the authors highlighted that some elements, known to be influenced by anthropogenic activities, merge into the geochemical background, like As. In contrast, $\mathrm{Cu}, \mathrm{Pb}$, or $\mathrm{Zn}$ did not follow the same trend due to the manmade more strongly influence, even in remote areas. A significant gradient from the South to the North-East was observed, convergently to the increased concentration registered in soils.

\section{Acknowledgements}

This project benefited from a financial support by ADEME (French Agency for Environment). The authors would like to thank the OMP ICP service (GET) and Rémi Freydier for complementary analyses. Thanks to Marie-Josée Tavella for the cleanroom service in EcoLab. Yannick Agnan is grateful for an ADEME fellowship. 

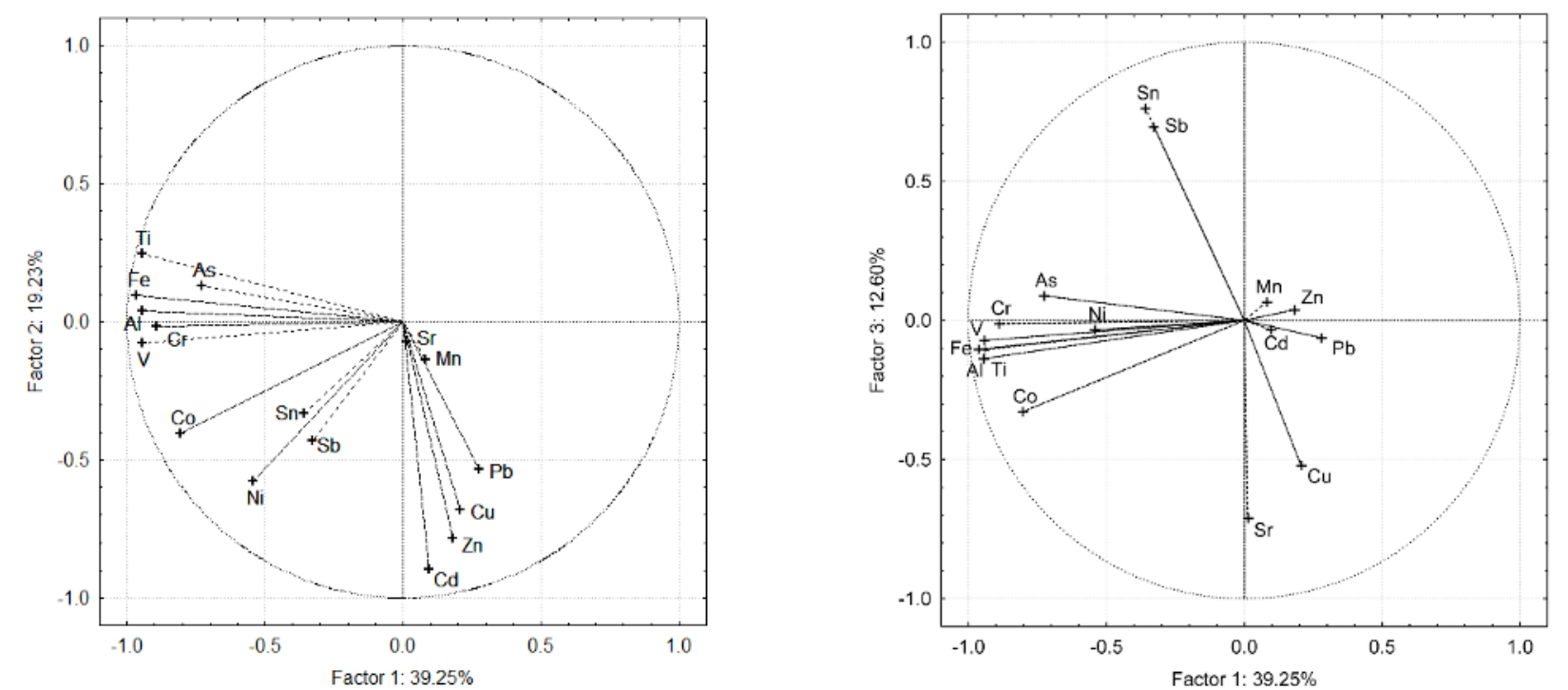

Fig. 2. PCA of 16 trace elements based on concentrations obtained in lichens for the five areas studied: factor 1 vs factor 2 (on the left) and factor 1 vs factor 3 (on the right)

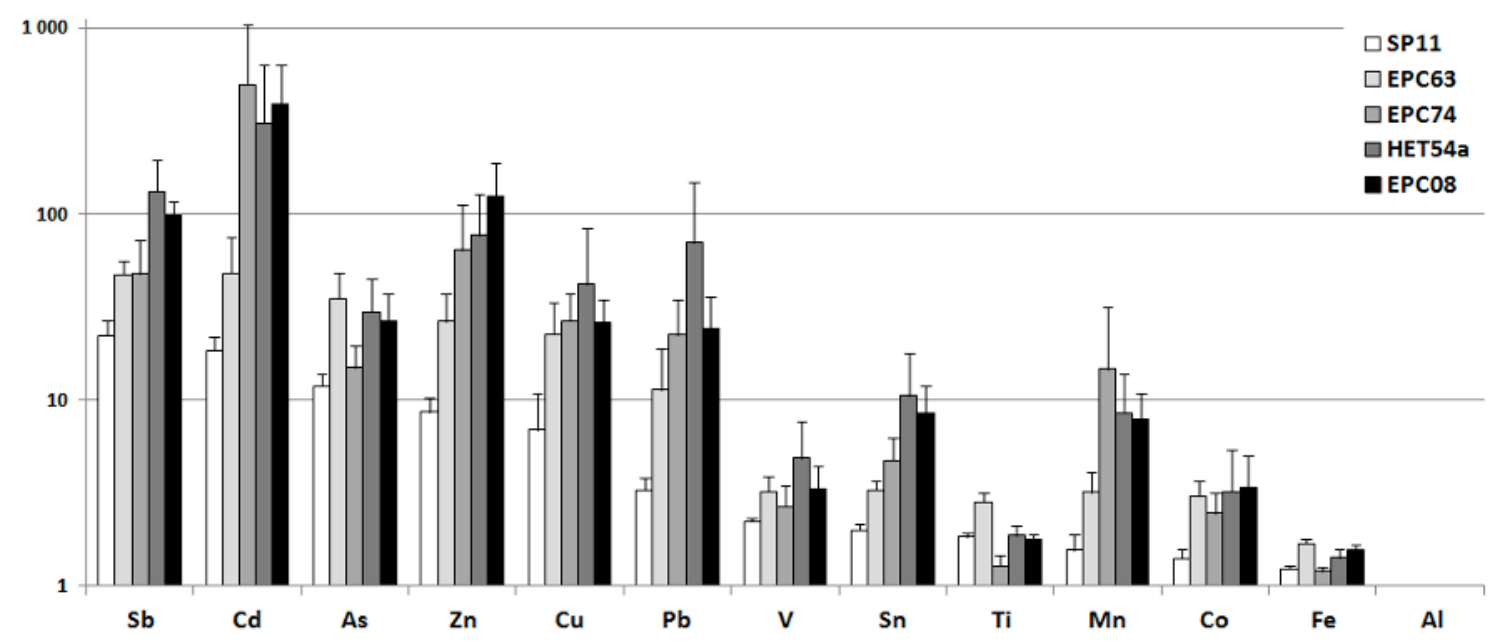

Fig. 3. Enrichment factor of 13 trace elements from lichens samples for the five stations studied (normalization: Al and UCC)

\section{References}

Bargagli R, Monaci F, Borghini F, Bravi F, Agnorelli C. Mosses and lichens as biomonitors of trace metals. A comparison study on Hypnum cupressiforme and Parmelia caperata in a former mining district in Italy. Environ Pollut $2002 ; 116: 279-87$.

Bergamaschi L, Rizzio E, Valcuvia MG, Verza G, Profumo A, Gallorini M. Determination of trace elements and evaluation of their enrichment factors in Himalayan lichens. Environ Pollut 2002 ; 120:137-44.

Brunialti G, Frati L. Biomonitoring of nine elements by the lichen Xanthoria parietina in Adriatic Italy: A retrospective study over a 7 -year time span. Sci Total Environ 2007 ; 387:289-300.

Chiarenzelli J, Aspler L, Dunn C, Cousens B, Ozarko D, Powis K. Multi-element and rare earth element composition of lichens, mosses, and vascular plants from the Central Barrenlands, Nunavut, Canada.
Appl Geochem $2001 ; 16: 245-70$.

Conti ME, Cecchetti G.. Biological monitoring: lichens as bioindicators of air pollution assessment - a review. Environ Pollut 2001 ; 114:471-92.

Falla J, Laval-Gilly P, Henryon M, Morlot D, Ferard JF. Biological air quality monitoring: A review. Environ Monit Assess 2000 ; 64:627-44.

Gandois L, Tipping E, Dumat C, Probst A. Canopy influence on trace metal atmospheric inputs on forest ecosystems: Speciation in throughfall. Atmos Environ 2010 ; 44, 824-33

Garty J. Biomonitoring atmospheric heavy metals with lichens: Theory and application. Crit Rev Plant Sci $2001 ; 20: 309-71$.

Hernandez L, Probst A, Probst JL, Ulrich E. Heavy metal distribution in some French forest soils: evidence for atmospheric contamination. Sci Total Environ $2003 ; 312: 195-219$.

Loppi S, Nelli L, Ancora S, Bargagli R. Passive monitoring of trace elements by means of tree 
leaves, epiphytic lichens and bark substrate. Environ Monit Assess 1997 ; 45:81-88.

Loppi S, Putorti E, Pirintsos S, De Dominicis V. Accumulation of heavy metals in epiphytic lichens near a municipal solid waste incinerator (Central Italy). Environ Monit Assess 2000 ; 61:361-71.

Lee K, Do Hur S, Hou S, Hong S, Qin X, Ren J, Liu Y, Rosman KJR, Barbante C, Boutron CF. Atmospheric pollution for trace elements in the remote high-altitude atmosphere in central Asia as recorded in snow from Mt. Qomolangma (Everest) of the Himalayas. Sci Total Environ 2008 ; 404:171-81.

Matschullat J. Arsenic in the geosphere - a review. Sci Total Environ $2000 ; 249: 297-312$.

Nimis PL, Lazzarin G, Lazzarin A, Skert N. Biomonitoring of trace elements with lichens in Veneto (NE Italy). Sci Total Environ 2000 ; 255:97-111.

Rauch JN, Pacyna JM. Earth's global Ag, Al, Cr, Cu, Fe, $\mathrm{Ni}, \mathrm{Pb}$, and $\mathrm{Zn}$ cycles. Glob Biogeochem Cycle $2009 ; 23: 16$ pp.

Rusu AM. Sample preparation of lichens for elemental analysis, in: Nimis PL et al. (Eds.), Monitoring with Lichens - Monitoring Lichens. Kluwer, Dordrecht ; 2002 ; pp. 305-9.

Rusu AM, Jones GC, Chimonides PDJ, Purvis OW.
Biomonitoring using the lichen Hypogymnia physodes and bark samples near Zlatna, Romania immediately following closure of a copper ore-processing plant. Environ Pollut 2006 ; 143:81-88.

Szczepaniak K, Biziuk M. Aspects of the biomonitoring studies using mosses and lichens as indicators of metal pollution. Environ Res 2003 ; 93:221-30.

Taylor SR, McLennan SM. The continental crust: its composition and evolution. Blackwell, Oxford ; 1985.

Ulrich B, Pankrath J. Effects of accumulation of air pollutants in forest ecosystems. D. Reidel Publishing Company, Germany ; 1983.

Vieira BJ, Freitas MC, Rodrigues AF, Pacheco AMG, Soares PM, Correia N. Element-enrichment factors in Lichens from Terceira, Santa Maria and Madeira Islands (Azores and Madeira archipelagoes). J Atmos Chem 2004 ; 49:231-49.

Wolff E, Suttie E, Peel D. Antarctic snow record of cadmium, copper, and zinc content during the twentieth century. Atmos Environ 1999 ; 33:1535-41.

Wolterbeek B. Biomonitoring of trace element air pollution: principles, possibilities and perspectives. Environ Pollut $2002 ; 120: 11-21$. 